\title{
Chronological Role of the Soil Research in Korea - Analysis of Research Reports on Soil from 1906 to 2012 -
}

\author{
Sun-Gang Yun*, Soon-Ik Kwon, Seung-Chang Hong, Min-Kyeong Kim, \\ Mi-Jin Chae, Chan-Won Park', and Goo-Bok Jung \\ Climate Change and Agroecology Division, National Academy of Agricultural Science, RDA, Suwon 441-707, Korea \\ ${ }^{1}$ Soil and Fertilizer Division, National Academy of Agricultural Science, RDA, Suwon 441-707, Korea
}

(Received: September 13 2013, Accepted: September 30 2013)

\begin{abstract}
Research reports on soil during the years from 1906 to 2012 have been analyzed to understand the role and pattem of soil research in agriculture. The number of research reports in relation with the key word of soils were 2,211 cases and classified in accordance with the criteria of research area, research subject, and research place of report papers. During the 40 years from 1906 to 1946, research work on soil chemistry was reached $62 \%$, highest in the research area. In the case of research subject, research reports on soil fertility and soil nutrients was highest as $42.2 \%$, and the next subject on soil salt and desalinization was about $19.5 \%$. Research places were in the order of paddy as $34.1 \%$, upland as $23.7 \%$, and reclaimed soil as $22.5 \%$. From 1953 to 2012 during 60 years, in the research area report papers were mainly concentrated on chemistry area as $32 \%$ and the next was physics as $26 \%$, and environment as $12 \%$. In the case of research subject during the same period, nutrient management report was reached $21.1 \%$, and soil improvement on chemical and physical properties for optimum crop growth was $11.9 \%$. Soil survey and data base establishment report was $8.6 \%$. Research place were in the order of upland as $34.9 \%$, paddy as $\mathbf{2 5 . 7 \%}$, and vinyl house as $12.5 \%$, which showed reversed pattem compared to that of before 40 years.
\end{abstract}

Key words: Soil, Environment, Agriculture, History of research

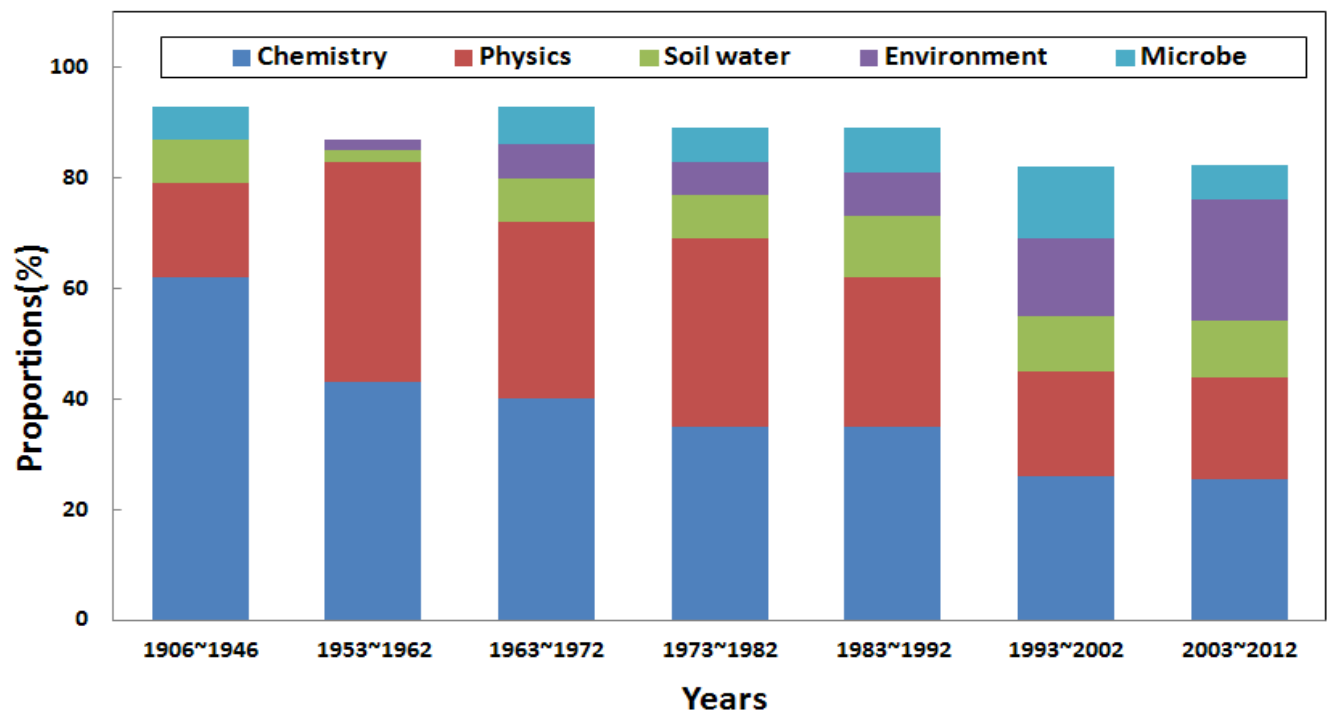

Proportions of research reports on soil classified in accordance with research area during the years from 1906 to 2012 in Korea.

\footnotetext{
*Corresponding author : Phone: +82312900218 , E-mail: sgyun@korea.kr

${ }^{\S}$ Acknowledgement: This study was carried out with the support of "Research Program for Agricultural Science \& Technology Development (Project No. PJ008507)", National Academy of Agricultural Science, Rural Development Administration, Republic of Korea.
} 


\section{Introduction}

농업에서 토양은 작물생산의 기반이 되는 요소이므로 토 양 연구는 농업이 직면한 시대적 상황에 대응하기 위하여 연구의 방향과 중점 주제의 방향이 결정되어 졌을 것이다. 한국토양비료학회에서 발간한 한국토양비료학회 30 년의 회 고와 전망 (1998)에서는 학회지에 투고된 논문 중심으로 토 양연구의 흐름을 분석한 사례가 있었으며, 이후에는 한국토 양비료학회 창립 40주년 기념 (2009)에서 토양에 관련한 10 개 분야에 대하여 연구논문의 동향을 자세하게 분석하여 보고 한 바 있다. 그러나 연구보고서를 통한 시대 흐름에 따른 토 양연구의 역할을 검토한 보고는 없었다.

따라서 본 논문에서는 과거부터 현재까지 수행되어 온 토양 연구의 흐름을 분석하여 우리 농업에 있어서 토양의 역할을 이해하고 기후변화와 같은 농업에 미치는 파급 영향 이 큰 환경의 변화에 미래지향적이고 능동적인 대응을 위한 참고자료로 활용하기 위하여 실시하였다.

\section{Materials and Methods}

농촌진흥청에서 구축해 놓은 연구 보고서 중 토양관련 자료는 1906년부터 2012년까지 수집, 정리하여 전산화되어 있었다. 본 논문은 우리의 농업에 있어서 시대적 변화에 따 른 토양의 역할을 고찰하기 위하여 연구보고서 항목에서 검 색어를 토양으로 선택하여 추출된 보고서를 가지고 분석하 였다. 이 중에는 토양비옥도조사사업, 농토배양사업, 산지 조사사업과 같이 전국적인 규모로 시행된 사업의 경우와 여 러 기관이 동일 제목으로 같이 진행된 연구과제의 경우 보 고서 제목이 유사한 것이 있었다. 이들은 동일 주제 보고서 로 간주하고 보정 작업한 결과 총 2,211 건이 분석에 이용되 었다. 연구내용은 연구분야별, 연구주제별, 그리고 농경지 이용형태별로 구분하여 분석하였다.

\section{Results and Discussion}

1906년부터 1946년 분야별로 보면 전체 보고서 중 비 옥도, 양분상태와 같은 화학성 관련 내용이 $62 \%$ 로 높은 비 율을 차지하였다 (Table 1). 주제별로 보면 토양 양분 관련 내용이 $42.2 \%$ 로 가장 많았고 그 다음이 염류·제염 내용으로 $19.5 \%$ 였다. 그리고 병 관련 내용이 $8.7 \%$ 였고 물 관리, 녹비 및 적지 관련 내용 순이었다. 농경지별로는 논이 $34.1 \%$, 밭 이 $23.7 \%$, 그리고 간척지 관련 내용이 $22.5 \%$ 에 해당되었다.

10년 단위별 1906년부터 1910년까지 보고서의 중점 내용은 산성토양에 대한 것이었고, 1911년부터 1920년까지 는 주로 개펄 (간석지)에서 제염과 가용성염류 함량에 대한
Table 1. Classification of research reports (173 cases) on soil in accordance with research area, subject and place during 40 years from 1906 to 1946 in Korea.

\begin{tabular}{lclclc}
\hline \multicolumn{2}{c}{ Area (\%) } & \multicolumn{2}{c}{ Subject (\%) } & \multicolumn{2}{c}{ Place (\%) } \\
\hline Chemistry & 62 & Fertility & 42.2 & Paddy & 34.1 \\
Physics & 17 & Soil salts & 19.7 & Upland & 23.7 \\
Soil water & 8 & Biology/Ecology & 8.7 & Reclaimed soil & 22.5 \\
Microbes & 6 & Water manage. & 6.4 & Paddy/Upland & 17.3 \\
Biology & 5 & Green crop & 5.2 & Orchard & 0.6 \\
Pesticide & 1 & Crop suitability & 4.6 & Forest soil & 0.6 \\
Others & 1 & Survey/DB & 2.9 & Others & 1.2 \\
& & Improvement & 2.9 & & \\
& & Soil testing & 2.3 & & \\
& & Disease & 1.7 & & \\
& Organic matter & 1.2 & & \\
& Behavoirs & 1.2 & & \\
& Others & 1.0 & & \\
\end{tabular}

내용이 많았다. 그 당시에 몇 개 인지는 확인되지 않지만 전 국에 산재한 농장들에 대한 토양의 이화학적 기초조사들이 보고되었다. 1921년부터 1930년까지는 간척지 조사가 시작 되었는데 간척지에 관개수를 넣어 염분을 제거하거나 녹비 작물을 재배하여 제염효과를 조사한 보고서가 다수 있었다. 또한 농사를 위한 토양 중 가용성 염류의 상태 조사에 대한 내용도 포함되어 있었다. 1931년부터 1940년까지는 간척지 에서 녹비작물의 재배에 관한 보고서가 다수를 이루고 있고 저위생산지, 노후화답, 부식 등 토양화학성에 대한 것들과 아울러 전국 농경지의 양분상태에 대한 조사 보고서들이 포 함되어 있었다. 1941년부터 1946년까지는 간척지에서 벼 생 산과 관련한 석회효과, 농경지 개량에 대한 조사와 밭 토양 에 대한 산도 교정과 인산 등 양분에 대한 조사 보고서들이 포함되어 있었다. 이 기간 동안에 이루어진 연구들은 주로 간석지 및 간척지의 제염에 집중되었고 토양의 양분 상태에 대한 조사들이었다.

1953년부터 2012년 1953년부터 2012년까지 전체 60 년 기간 동안 토양관련 연구보고서의 전체적인 흐름은 Table 2 와 같다. 이 기간 동안에 연구보고서는 총 2,038 건 에 해당되며 전체적으로 보고서의 내용을 구분하여 그 비율 을 살펴보았다.

연구분야별로 차지하는 보고서의 비율은 화학 $32 \%$, 물리 $26 \%$, 환경 $12 \%$ 이었으며 그 다음으로는 물 관리, 미생물. 병, 생물, 농약, 정보화 순이었다. 화학 분야가 많은 비중을 차지했던 것은 당시에 비교적 척박한 우리나라 토양 조건에 서 필요량의 작물을 생산하기 위하여 양분관리와 비료 사용 량 조건 등에 대한 수요가 많아서 비옥도 관련 연구가 주류 
Table 2. Classification of research reports $(2,038$ cases) on soil in accordance with research area, subject and place during 60 years from 1953 to 2012 in Korea.

\begin{tabular}{|c|c|c|c|c|c|}
\hline \multicolumn{2}{|c|}{ Area $(\%)$} & \multicolumn{2}{|c|}{ Subjects (\%) } & \multicolumn{2}{|l|}{ Place (\%) } \\
\hline Chemistry & 32 & Fertility & 21.1 & Upland & 34.9 \\
\hline Physics & 26 & Improvement & 11.9 & Paddy & 25.7 \\
\hline Environment & 12 & Survey/DB & 8.6 & Vinyl house & 12.5 \\
\hline Soil water & 9 & Water manage. & 7.8 & Orchard & 8.1 \\
\hline Microbes & 8 & $\begin{array}{l}\text { Pollution/ } \\
\text { Residue }\end{array}$ & 6.3 & Paddy/Upland & 7.1 \\
\hline Biology & 6 & Crop suitability & 6.1 & $\begin{array}{l}\text { Forest/ } \\
\text { Grassland }\end{array}$ & 4.8 \\
\hline Pesticides & 3 & Disease & 5.9 & Reclaimed soil & 3.2 \\
\hline Information & 3 & Bioecology & 5.8 & Others & 3.7 \\
\hline \multirow[t]{9}{*}{ Others } & 1 & Soil testing & 4.3 & & \\
\hline & & Erosion & 3.9 & & \\
\hline & & Organic matter & 3.5 & & \\
\hline & & Soil salts & 3.1 & & \\
\hline & & Livestock waste & 1.5 & & \\
\hline & & Behavoirs & 1.4 & & \\
\hline & & Rotational crop & 1.3 & & \\
\hline & & Green crop & 0.4 & & \\
\hline & & Others & 7.1 & & \\
\hline
\end{tabular}

를 이루어 졌다고 생각된다. 물리 분야가 $26 \%$ 를 차지하였는 데 토양관리에 있어서 토양 개량과 산지나 개간지 등의 농 경지로서 사용여부에 대한 토양조사 그리고 토양유실과 방 지에 대한 연구가 대부분 이었다. 다음이 환경 분야로 $12 \%$ 를 차지하였는데 1980 년대에 접어들면서 환경 분야의 보고 서 수가 늘어나기 시작하였다. 가축분뇨나 산업분야에서 발 생한 유기성 폐자원 등의 재활용 효과 및 중금속류와 관련 한 연구보고들이 대부분 이었다. 산업화와 함께 농업환경에 미치는 직 - 간접적인 영향이 증가하면서 토양 분야에서 환 경이 중요한 부분을 차지하게 되었고 최근 환경 분야의 보 고가 다수 증가하고 있다. 생물 분야는 $6 \%$ 에 해당되는데 토 양과 관련한 작물품종 시험이나 녹비, 영양생리, 생육장애, 조직배양 등이 이에 포함되었다.

연구 주제별 분류 1953년부터 2012년까지 연구 주제 별 분류는 보고서 제목의 특성에 따라 가능한 주제를 세분 화하여 최종적으로 16 개로 구분하였다 (Table 2). 연구 주제 별로 분류한 결과, 비료사용과 비옥도 관련한 양분관리가 $21.1 \%$ 로 가장 많았는데 이는 작물생산을 위한 토양 중 양 분의 상태 파악 및 다수확을 위한 재배 노력이 집중적으로 이루어져 왔다고 생각된다. 작물의 생산량 증진을 위하여 지대별 벼 다수확기술, 국내 농경지의 비옥도 파악, 산성토
양 석회사용량 설정기준, 비료 종류별 적정사용량 기준, 토 양양분과 작물생육과의 관계구명, 토양양분의 유효도 등이 주요 연구 주제로 수행되었다. 통일벼가 개발된 1970년대 이전에는 다수확 재배를 위한 지역별 토양 양분관리 연구가 수년간 진행되어 적정 토양관리 기술들이 적시에 적용되어 왔다고 생각된다. 1980년대 이후부터는 농산물의 품질 향상 과 관련된 양분관리와 가축분뇨 등의 여러 가지 유용한 유 기성 자원들의 비료대체 자원으로서 활용에 대한 연구들과 농촌생산 현장에서 농경지의 토양을 분석하여 필요한 비료 사용량을 결정하는 체제를 마련하기 위한 연구가 이루어졌 다. 또한 비닐하우스 재배가 도입되면서 채소과 같이 시설 에서 재배되는 작물에 필요한 재배기술로서 시설토양에 대 한 양분관리에 대한 비중이 많아졌고 소비자들의 선호가 높 아진 과수, 채소, 화훼 같은 특화작목의 경우 작목별 비료사 용 기준 등을 설정하는 연구 주제들이 많았다. 토양 개량분 야는 $11.9 \%$ 를 차지하였는데 척박한 토양의 지력을 향상하기 위하여 개량제의 개발과 이에 대한 효과 검정이 주류를 이 루었다. 토양개량 연구는 1970 년대 초반에 가장 높았고 이 후 $15 \%$ 내외로 유지되다가 2000 년대 들어서 감소하는 추세 였다. 이에 못지않게 중요한 분야가 전국에 분포하는 농경 지와 산지에 대한 토양 조사 및 $\mathrm{DB}$ 사업으로 $8.6 \%$ 를 차지하 였다. 이는 현재 전 세계적으로 유일하게 구축되어 있는 토 양전자지도 (흙토람)를 마련하게 된 토양조사 기초자료를 확보할 수 있는 발판이 되었다. 그 다음이 $7.8 \%$ 를 차지하는 물 관련 연구로 오염 및 농약잔류 관련, 작물재배 적지관련, 병해충, 생물생태, 토양검정, 토양유실, 유기물, 토양염류 와 제염, 가축분뇨 사용, 양분의 토양 중 행동해석, 답전윤 환, 척박한 토양개량과 더불어 비료를 대체하기 위한 녹비 작물에 관한 연구의 순이었다. 기타 주제로는 유기농, 작부 체계 토양관리, 자재, 분석, 연작 등이었다.

연구대상이 농경지에 대한 연구는 밭이 $34.9 \%$, 논 $25.7 \%$, 그리고 시설재배지가 $12.5 \%$ 순으로 주를 이루었으 며 이 외에도 과수토양, 산지초지, 간척지 순으로 연구가 수 행되었다. 연구보고서 비율로 볼 때 논 연구가 밭 연구에 비 하여 적었는데 이는 논 연구의 대상이 벼 단일 작목연구인 데 반해 밭작물은 대상 작물이 다양하고 많기 때문에 밭에 대한 토양연구가 가장 많았던 것으로 생각된다. 시설재배지 에 토양연구는 전체의 $12.5 \%$ 를 차지하였는데 산업화와 도 시화 그리고 소비자들의 식문화 선진화와 더불어 다양한 채 소류의 사계절 생산 공급을 위한 시설 내에서의 비료사용량 결정, 토양 비옥도관리, 염류축적 및 수분관리 등과 관련한 토양관리 기술 수요가 많았기 때문이라고 생각된다.

전체기간에 대한 $\mathbf{1 0}$ 년 주기별 분석결과 Fig. 1은 1906 1946년 전체를 한 주기로 하고 1953 2012년까지는 10 년 단위 주기로 세분하여 연구분야별 보고서의 비율을 나 


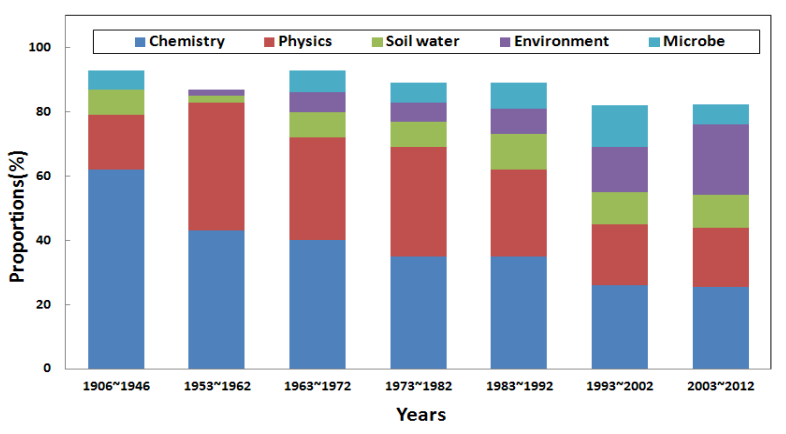

Fig. 1. Proportions of research reports on soil classified in accordance with research area during the years from 1906 to 2012 in Korea.

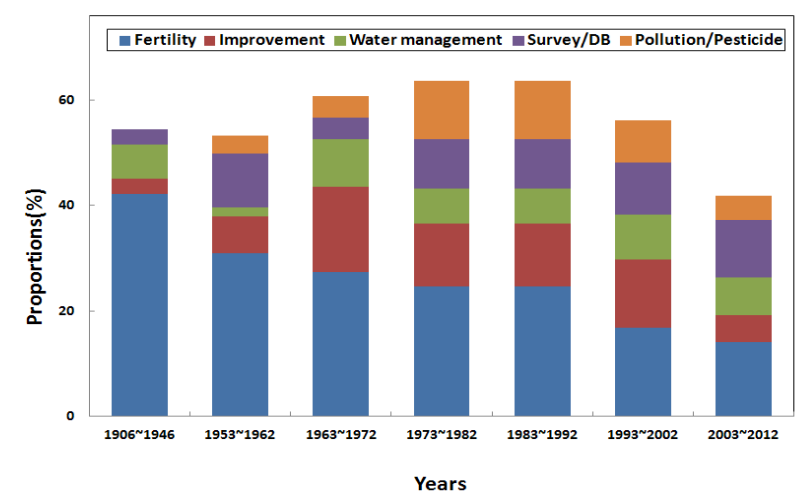

Fig 2. Proportions of research reports on soil classified in accordance with research subject during the years form 1906 to 2012 in Korea.

타내었다.

토양화학 분야는 1946 년 이전까지는 거의 $60 \%$ 이상을 차 지하였다가 그 이후부터는 점차 비중이 줄어들었다. 그럼에 도 불구하고 가장 높은 비율을 차지하고 있었다. 반면 토양 물리 분야는 1940 년대 까지는 $18 \%$ 수준이었으나 1950년대 에는 $42 \%$ 까지 증가하다가 토양화학분야와 함께 유사한 경 향으로 완만하게 줄어드는 추세를 보였다. 1950년대를 전환 점으로 화학과 물리분야의 연구보고서 패턴을 볼 때 당시의 토양조건이 열악한 상태에서 식량생산을 위하여 비옥도와 양분관리 같은 화학분야에 집중하였다가 1960년대부터는 물 관리와 환경 분야 그리고 토양 미생물과 병 및 생물 등의 분야에 연구가 증가되는 경향을 보였다. 그리고 2000년대 에 들어서는 여러 분야가 비슷한 비중을 갖고서 연구가 진 행되어지는 패턴을 보였다. 이는 농업에 있어서 토양의 역 할이 안정적인 작물생산과 더불어 농경지에서의 오염 문제 나 가축분뇨와 같은 부산물들의 재활용 등 다양한 환경문제 에 대한 대응 및 안전한 농산물 생산을 위한 사회적 요구에 부응하여 온 것 때문이라고 생각된다. 또한 토양연구에 있 어서 기초적인 분야와 더불어 농업과 농촌에 현장문제의 해 결과 같은 연구에 많은 노력들이 모여지고 있었기 때문이라 고 생각된다.
Fig. 2는 연구 주제별 분류에서 비교적 비중이 높았던 5 개의 주요 주제별 (양분, 개량, 물관리, 토양조사/DB구축, 오염/농약잔류/환경)로 년수 경과에 따른 보고서 비율의 변 화를 나타낸 것이다. 토양양분 관련 연구가 전체기간 동안 높은 비율을 차지하였는데 이는 우리의 토양조건이 모암의 유래를 볼 때 산성을 띠고, 지형과 여름 다우의 기상 하에서 양분의 유실이 많을 수밖에 없는 여건이라고 생각된다. 따 라서 여러 가지 다양한 종류의 농작물에 대한 안정생산을 위하여 필수적으로 지속적인 토양 양분상태에 대한 진단이 이어지고 이에 따른 필요 양분의 공급을 유지함으로서 토양 의 비옥도를 적정 수준으로 유지해야 하는 상황임을 간접적 으로 보여 주고 있는 것이라고 생각된다. 1960년대부터 지 속적으로 늘어나는 토양개량 분야의 비중이 이를 반증해 주 었는데 배수 및 석회 사용과 같은 알칼리 자재의 투입과 물 리, 화학적 개량을 통하여 작물생산을 위한 최적의 토양조 건을 만들기 위한 노력의 결과라고 생각된다. 특히 식량 증 산의 노력이 활발했던 1970 년대에 토양개량의 연구가 전체 의 $20 \%$ 에 이를 정도로 높은 비율을 차지하였다.

Fig. 3은 연구가 수행된 농경지의 이용형태별 연구보고 서의 비율을 나타낸 것이다. 논에 대한 연구는 1940 년대 이 전에 $35 \%$ 정도로 많았다가 1950년대 중반에는 낮아졌다. 그리고 1950년대 이후부터 1970년대 초반까지 다시 급격하 게 증가하는 추세를 보였는데 이는 이 시기에 식량증산과 관련한 많은 노력들이 기울여져 왔다고 생각된다. 1980년대 이후부터는 논에 대한 연구비율이 점차적으로 감소되었는 데 상대적으로 이 시기 동안 밭과 시설재배에 대한 연구가 역으로 증가하였다. 이는 당시 식생활 개선과 더불어 고추, 마늘 등 다양한 밭작물과 채소류의 수요가 많아지고 1993년 에는 전 세계적으로 시장개방의 물결에 따라 UR 협상이 타 결되어졌고, 그 이후에는 FTA 등이 체결되어 지면서 전반 적으로 농산물 수입에 대응하기 위한 노력이 집중되어졌다 (정영일, 2013). 밭작물과 시설재배 작물은 농산물 수입에 대응하기 위하여 다양한 전략으로 여러 가지 품목에 대한

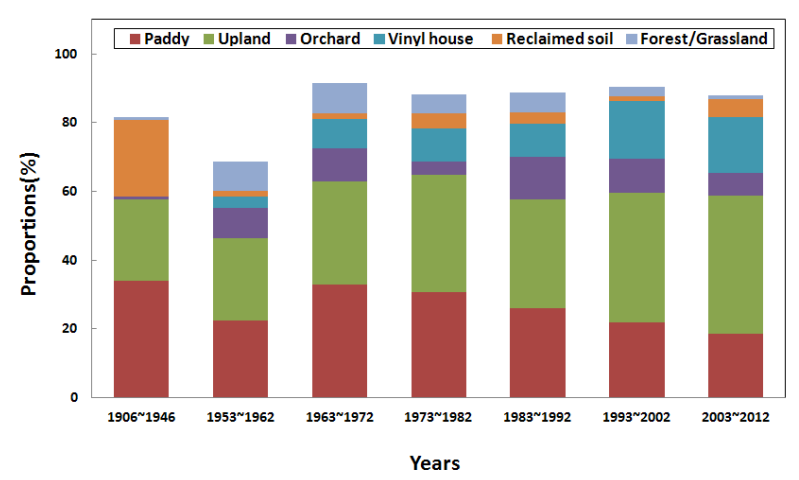

Fig. 3. Proportions of research reports on soil classified in accordance with research place during the years from 1906 to 2012 in Korea. 
연구가 진행되면서 이 분야에 대한 시설분야에 대한 토양연 구도 증가되었던 것으로 생각된다. 간석지와 간척지에 대한 연구는 1940년대 이전에는 아주 높은 비율을 차지하다가 1950 년대 이후에 급격히 감소 후 다시 2000년대 초기 이후 부터 간척지의 조기 숙전화와 농경지로서 활용과 관련한 연 구 등이 증가한 결과라고 생각된다.

\section{References}

Korean Society of Soil Science and Fertilizer. 1998. Korean
Society of Soil Science and Fertilizer's review and prospect over 30 years. Suwon, Korea. (In Korean)

Korean Society of Soil Science and Fertilizer. 2009. The $40^{\text {th }}$ anniversary of Korean Society of Soil Science and Fertilizer. Suwon, Korea. (In Korean)

Jung, Y.I. 2013. Review, Prospect and Subject of Agricultural Administration in Korea. The $20^{\text {th }}$ anniversary Symposium. Center for Food, Agricultural, and Rural Policy. Seoul, Korea. (In Korean) 